\title{
Normal tension glaucoma: review of current understanding and mechanisms of the pathogenesis
}

\author{
HE Killer ${ }^{1} \cdot$ A Pircher ${ }^{1}$
}

Received: 19 December 2017 / Revised: 26 January 2018 / Accepted: 26 January 2018 / Published online: 19 February 2018

(c) The Royal College of Ophthalmologists 2018

\begin{abstract}
Normal tension glaucoma (NTG) is an exception in the "glaucoma family" where the major risk factor, increased intraocular pressure, is missing. If not increased intraocular pressure, then what other causes can then lead to glaucomatous optic disc change and visual field loss in NTG? Several possibilities will be discussed. Among them a higher sensitivity to normal pressure, vascular dysregulation, an abnormally high translaminar pressure gradient and a neurodegenerative process due to impaired cerebrospinal fluid dynamics in the optic nerve sheath compartment. There are many excellent review papers published on normal tension glaucoma (NTG). The aim of this paper is therefore not to add another extensive review on NTG but rather to focus on and to discuss some possible mechanisms that are thought to be involved in the pathophysiology of NTG and to discuss the stronger and weaker aspects of each concept. The fact that several concepts exist suggests that NTG is still not very well understood and that no single mechanism on its own might adequately explain NTG.
\end{abstract}

\section{Introduction}

The term "normal tension glaucoma", to begin with, is somehow an unhappy one, as historically the term glaucoma is strongly associated with elevated intraocular pressure (IOP). Elevated IOP is considered to be the mechanical force causing optic disc cupping and visual field loss due to pressure-induced damage to retinal ganglion cells and retinal axons. Therefore, whenever the term glaucoma is involved, one tends to associate it with the mechanical force pressure. But the concept of NTG is neither understood nor is it solved by looking at pressure as a sole cause [1-4]. Trying to do this means to oversimplifying the problem. Several reasons will explain why.

Pressure is a scalar force and therefore unlike a vector, it is not directed. Visual field damage caused by a scalar force would therefore be expected to be rather homogenous over the whole visual field, as the shape of the eye is spherical and the scalar force is the same at every point in the sphere. Visual field loss in glaucoma, however, does not present as

HE Killer

Killer@ksa.ch

1 Department of Ophthalmology, Cantonal Hospital,, 5001 Aarau,, Switzerland a generalized homogenous defect but it rather starts at focal points from where it enlarges [5-7]. Caprioli and Späth [8] found visual field defects in NTG to be significantly deeper and closer to fixation than in other types of glaucoma. To explain such focal defects, some authors argue that certain populations of ganglion cells and axons react more sensitively to pressure than others [9]. But even if this is the case, such "more sensitive regions" seem to vary between patients. Further, if the IOP is indeed the sole cause for glaucomatous damage in NTG, progression of damage would be expected to stop when the pressure is maximally lowered. This, however, is not the case. Given that there are no data on what the lowest pressure should look like and how it could be achieved, remains an unsolved problem. Further controlled studies may however answer this question about the ideal target pressure in the future.

Glaucoma is the most frequent disease of the optic nerve and the second leading cause for blindness $[10,11]$. It is in fact the most common «neuro-ophthalmological entity». Glaucoma has been known since Antiquity when it first was described as "hardness of the eyeball". In 1862, Donders discovered that high IOP can lead to blindness and he named the disease "Glaukoma simplex" [12]. In the 1850s, Von Graefe described for the first time a condition that is now referred to as normal or low-tension glaucoma [13]. In the early 1900s, applying tonometry and ophthalmoscopy 
NTG was recognized as a new clinical entity [12]. Due to the lack of understanding of the underlying pathophysiology of NTG a variety of terms, such as pseudoglaucoma, paraglaucoma, low-tension glaucoma or glaucoma without high pressure and arteriosclerotic optic atrophy have been coined. Intriguingly, we know today that glaucomatous optic disc excavation and visual field loss is found, varying with age, in 30-90\% [14, 15], of patients with IOP within a normal range, a condition that is now named NTG. Given the complexity of the pathophysiology of NTG, probably a term like "normal tension glaucomatous optic neuropathy" would be more fitting.

This observation raises some intriguing questions. If glaucoma is considered to be a disease of the optic nerve caused by elevated IOP leading to damage of retinal axons, ganglion cells and optic disc excavation, then how is it possible that disc cupping and visual field loss also develop without statistically elevated IOP, presenting with the same morphological appearance of the optic disc as seen in high pressure-induced glaucoma?

What other pathophysiological pathways, if not elevated IOP, might be involved in the damage observed in NTG cases. Where is the primary site of damage? Could it be in the preganglion axon, the retinal ganglion cell or the postganglion axon? Does optic atrophy in NTG follow an anteriograde or a retrograde direction or both?

In order to answer these questions, several concepts have been developed over time. They can be summarized basically in the following groups.

- Some people are more sensitive than others to IOP? Thus, in NTG normal IOP leads to mechanical damage and to stress on the axons in the lamina cribrosa.

- NTG is caused by local or generalized vascular dysregulation.

- NTG is caused by a higher than normal pressure gradient across the lamina cribrosa.

- NTG is caused by impaired CSF circulation in the subarachnoid space of the optic nerve and this results in a toxic damage to the nerve.

The fact that none of these theories is able to render an all conclusive and unanimous explanation for NTG, demonstrates that the pathophysiology of NTG might be multifactorial. In fact, the main common factor in all these theories is contradiction. Additionally, in most studies the statistical power is missing. This is of importance as the interpretation of most theories is based on correlations rather than on causations.

Obviously, a change in statistical power will change the results of such studies quite drastically.

\section{Mechanisms of the pathophysiology of} normal tension glaucoma

\section{Lower tolerance of normal IOP causes mechanical damage}

As the effect of IOP might have a different impact in different populations and in different individuals, the amount of tolerated pressure may differ between groups and individuals [16, 17]. Compared with Caucasians, NTG is more frequent in Asia. Some studies report 52-92\% of all glaucoma cases, depending on the country and the methodology of the study [15]. In a study of a Zulu population in South Africa [18], normal IOP was reported in $57.1 \%$ of all primary open angle glaucoma (POAG) cases. The incidence in white populations was found to be $30-39 \%$ in studies performed in the United states [14], the Netherlands [19] and Italy [20]. This demographic difference seems to point toward a genetic component of NTG and/or a variable susceptibility to IOP in different populations.

In order to determine the role of IOP in NTG, the "Collaborative Normal-Tension Glaucoma Study" [16] was initiated. One eligible eye of 145 subjects with NTG was randomized either to no treatment (control) or to a $30 \%$ IOP reduction from baseline. After 3 years, an overall analysis showed a survival of $80 \%$ in the treated arm and $60 \%$ in the control arm. The 5-year survival figures were $80 \%$ in the treated arm and $40 \%$ in the controls. The Kaplan-Meier curves were significantly different $(P=0.0018)$. Visual field loss appeared in both groups, 22/66 in the treated and $31 / 79$ in the untreated group. Although the difference was statistically significant the clinical relevance seemed less impressive. It became evident that although pressure lowering of $30 \%$ can be beneficial in some patients, it did not stop the progression in all patients. Therefore, pressure alone can not explain the optic nerve degeneration in NTG as a sole factor.

Certain authors have argued that there might be a slightly different morphology of the NTG optic nerve head [21, 22]. Applying new diagnostic tools, such as Heidelberg retina tomography (HRT) some studies suggest that the discs may be larger and the cups deeper in NTG patients than in patients with high pressure-induced POAG [23, 24]. Whether or not this is true in all populations is still a matter of debate.

Another "mechanical" concept in the pathophysiology of glaucoma is focused on the lamina cribrosa [25, 26]. The lamina cribrosa is a crucial structure on the pathway of the intraocular axons to the intraorbital portion of the optic nerve. The nutrition of the axons within the lamina cribrosa is considered to be dependent on oxygen and nutrition from the capillaries within the lamina cribrosa. Damage to axons, capillaries and astrocytes in the biomechanical paradigm is 
thought to be caused by lamina cribrosa deformation and IOP-related stress and strain onto axons, capillaries and astrocytes within the lamina cribrosa [25]. Experiments in animals showed that the optic nerve head rim tissue thinning exceeds peripapillary retinal nerve fiber thinning [27]. The appealing part of this concept is that it could explain the pattern of visual field loss in glaucoma. The obvious question however is, if vascular damage is considered in this concept why does the optic nerve head not show cotton wool spots?

Further, central corneal thickness has been discussed as a clinical risk factor in NTG. Several studies [28-30] showed a thinner mean central corneal thickness in NTG patients compared with patients with ocular hypertension (OHT), high-tension POAG and normal eyes while other studies [31-33] did not find a difference. While a Japanese study [34] found an association between central corneal thickness and the mean deviation of visual field defects in NTG patients, another study did not find a relationship between central corneal thickness and the visual field loss or visual field progression [35].

Although IOP lowering has some beneficial effect on the progression of NTG in some patients while progression continues in others, (different thresholds?) there is, however, no known mechanism that could explain what causes a lower threshold for pressure-induced damage in some patients. This of course should not prevent ophthalmologists from lowering IOP in their patients.

\section{Perfusion deficit and vascular dysregulation}

Another theory to consider for the pathogenesis of glaucoma and in particular of NTG is the vascular theory. In 1858 , von Jaeger suggested that optic nerve damage due to elevated IOP was mediated by ischemia instead of mechanical compression of the optic nerve fibers [36]. Indeed, several studies revealed that insufficient blood supply leads to retinal ganglion cell loss [37-39]. Chronic ischemia and reperfusion (vascular dysregulation) damage were thought to be involved [40].

Insufficient blood supply might be due to either increased IOP or due to other systemic and local factors that reduce the ocular blood flow [41].

Low systemic blood pressure, particularly nocturnal low blood pressure has been reported to occur more commonly in patients with NTG $[42,43]$. Other studies found that low blood pressure as well as circadian fluctuations of the mean ocular perfusion pressure were major risk factors for the progression of visual field defects in NTG [44-47]. Low systemic blood pressure will lead to a decrease in ocular perfusion pressure with reduced ocular blood flow that consequently result in decreased blood supply to the optic nerve fibers. This is especially true for blood pressure „dippers" during the night.

Vascular dysregulation is suggested to be a main factor in the vascular pathophysiology of glaucomatous optic neuropathy, particularly in NTG [41]. Vascular dysregulation is defined as the inability of a tissue to maintain a constant blood supply despite changes in perfusion pressure. Vascular abnormalities and abnormal vascular reaction to local vasospastic and vasodilating agents were discussed. This includes vascular and endothelial diseases [48], vasospasm syndrome $[49,50]$ and migraine. All of these were reported as risk factors for optic nerve damage as seen in glaucoma without elevated IOP [51-53]. The collaborative NTG study group [51] and other studies [54] identified that a history of migraine and the appearance of optic disc hemorrhages were associated with a faster progression of visual field loss. This points towards a vascular component in NTG. The fact that disc hemorrhages can persist for a longer time may indicate that the bleeding may not be a one time effect, but has a more continuous character (private communication with Josef Flammer). It is suggested that vascular dysregulation leads due to an unstable ocular blood flow, resulting in ischemia and to optic nerve damage [55].

There is further indirect evidence of altered blood flow in NTG patients: A much higher prevalence of sleep apnoea-hypopnea syndrome in NTG patients [56, 57], compromised peripheral endothelial cell function $[48,58]$ and increased plasma levels of endothelin-1 (ET-1) [59-61]. Although upregulated ET-1 levels are considered a risk factor for NTG, there are data in a Japanese study that show no difference of ET-1 levels between NTG, POAG and normal adults under 60 years of age [62].

In summary, several experimental and clinical studies have shown impaired ocular blood flow in NTG. However, it is still not clear whether reduced blood flow is a primary cause or consequence of glaucomatous optic nerve changes.

\section{Translaminar pressure gradient}

Intraocular pressure is not the only pressure that might be involved in the pathophysiology of glaucoma. While IOP exercises a force from within the eye (anteriograde) onto the lamina cribrosa, cerebrospinal fluid is the counterforce at the back side of the lamina cribrosa.

A crucial anatomical site for glaucomatous damage might be the lamina cribrosa [63, 64]. Here the nonmyelinated axons cross from intraocular to the retrolaminar site through a sieve-like collagen structure, where the axons are located within the subarachnoid space, which is filled with cerebrospinal fluid. The lamina cribrosa and the optic nerve axons are, therefore, located between two pressure zones, intraocular pressure (IOP) and intracranial pressure (ICP). The difference between these two pressures is 
expressed as translaminar pressure (IOP - ICP) [65]. For a more accurate description, the intraorbital pressure should be considered as well, as it influences the pressure in the subarachnoid space of the optic nerve that is referred to as intracranial pressure [66]. As measurements of the intraorbital pressure, however, are invasive, they are not applied in a clinical setting.

Cerebrospinal fluid pressure as a potential contributor to glaucoma was first considered in 1908 by K.I. Noishevsky, a Russian ophthalmologist in a dog model and found its renaissance in the 1970s [67]. Two more recent studies [68, 69] using lumbar puncture, one performed in an Asian and the other in an American population demonstrated in a small study population a significantly lower ICP in patients with NTG compared to high-tension glaucoma and normals. However, in two other studies, a homogeneous group of 39 Caucasian NTG patients from Switzerland [70] as well as in 13 NTG patients from Sweden [71], the ICP was within a normal range. Ren et al. [68]. found a positive correlation between the translaminar pressure and the neuroretinal rim area and mean visual field defects in Chinese patients with POAG (including 13 patients with NTG) and in patients with OHT. Other studies performed in 39, respectively, 11 NTG patients did not find any significant correlation between the mean visual field defects and the translaminar pressure [70, 69]. A recently published prospective case control study [71] on 13 NTG patients showed neither an elevated ICP, TLP nor a correlation between visual field defects and ICP and TLP in patients with NTG.

The concept of the translaminar pressure gradient as a risk factor is interesting but there are some methodological problems that need to be solved in order to get more accurate measurements. First, cerebrospinal fluid pressure is not measured behind the lamina cribrosa but in the lumbar spine. Given an open CSF pathway, this may render reliable results, but there are good reasons to believe that the system is not necessarily fully communicating. Secondly, IOP and CSF pressure fluctuate. In order to have phase synchrome data they need to be measured simultaneously. This might be achieved with noninvasive CSF pressure measurements. However, if more research is done on the translaminar pressure concept, more accurate methods need to be developed: local CSF pressure measurements and proper calculation of the area under pressure.

\section{Impaired cerebrospinal fluid circulation (compartment syndrome)}

Blood is not the only fluid that is important for a healthy optic nerve. Unlike other cranial nerves the optic nerve is surrounded completely by CSF and therefore exposed both to CSF pressure and content. The functions of CSF include protection against mechanical damage to the brain and the optic nerve, nutrition of neurons, axons and glial cells as well as a removal for biological debris [72].

Reduced turnover of CSF with consecutively elevated ABeta- and Tauprotein levels has been suggested to be one of the risk factors for Alzheimers disease [73, 74]. A decrease in CSF dynamics can cause a rise in such toxic protein concentrations [74-76]. Recent research demonstrated an age-dependent overlap of glaucoma and Alzheimers disease [77-79].

In order to maintain the homeostatic micro environment for the neural tissue, CSF is recycled up to 5 times a day [72]. Stagnation of CSF and impaired CSF dynamics are considered to be part of the pathophysiology of neurodegenerative diseases such as Alzheimers disease[76, 80, 81]. There is in fact an overlap of patients with Alzheimers and NTG [82, 83]. Studies in patients with NTG applying computertomographic-assisted cisternogaphy demonstrated largely reduced concentrations of contrast-loaded CSF in the subarachnoid space of the optic nerve [84]. Further, a study [85] on optic canal diameter demonstrated more narrow optic canals in NTG patients than in normal controls, thus suggesting an anatomical predisposition for a bottle neck situation for CSF dynamics from intracranial to the orbital SAS of the optic nerve. In addition, a large concentration gradient of betatrace protein was found between the lumbar CSF and the CSF in the orbital SAS of the optic nerve [86]. Interestingly, a difference in protein content was also found in the anterior chamber of glaucoma patients compared to a non-glaucoma group [87, 88]. In an experimental study [89] in sheep, the optic nerve was slightly ligated close to the optic canal to create an optic nerve sheath compartment. The animals were killed after several months and the optic nerves were examined. Loss of axons and a proliferation of meningothelial cells were found on the arachnoid mater. The most impressive damage was found close to the lamina cribrosa and not at the site of the ligature. Right behind the lamina cribrosa, the axons lack a myelin sheath and at the same location, the highest concentration of mitochondria is found [90]. It is feasible that the compartmentalization leads to highly impaired CSF turnover and to a toxic damage at that vulnerable site [91].

A genetic predisposition is suggested to be involved in NTG as well and more than 20 loci have been linked to POAG [92]. Among these genes, mutations in optineurin $(O P T N)$ and copy-number variations of TANK binding kinase $1(T B K 1)$ were identified as causative genes for NTG [93-95]. Interestingly, both proteins are involved in autophagy processes, processes in which intracellular accumulated proteins, organelles or pathogens are eliminated [96, 97].

The concept of impaired CSF dynamics leading to a change in pressure, velocity and content of stagnated CSF brings NTG closer to neurodegenerative disorders such as 
Alzheimers disease [77, 98, 99]. A recent study found diffuse brain damage in patients with NTG [100] while another study [77] describes NTG as a non memory associated variant of Alzheimers disease. NTG might in fact be the first manifestation of Alzheimers disease in a compartmentalized CSF within the cul de sac like subarachnoid space of the optic nerve.

\section{Conclusion}

Normal tension glaucoma (NTG) is an optic nerve neuropathy that presents with optic disc excavation, visual field loss in spite of intraocular pressure $<21 \mathrm{~mm} \mathrm{Hg}$. Progressive visual field loss and disc excavation can continue despite of pressure lowering of $30 \%$ of IOP. There are however, also a substantial number of patients who do not progress even without treatment. A substantial number of older NTG patients also suffer from Alzheimers disease, a finding that raises the question whether or not NTG is an early manifestation of a more generalized neurodegenerative disease. At the same time, some NTG patients share features of vascular dysregulation, which raises the question whether NTG is an optic nerve disease in a diseased body. In analogy therefore NTG might be a diseased optic nerve in a toxic CSF environment.

None of the current pathophysiological concepts can explain this intriguing condition on its own. It is most likely that NTG is a complex syndrome consisting of a variety of pathological pathways that may differ between populations and individuals. Further research should focus on translational research that will lead to a more individualized therapeutic approach.

Acknowledgements We thank Dr. Julian Stekhoven for helpfull comments on the manuscript as well as for assistance with the language.

\section{Compliance with Ethical Standards}

Conflict of interest The authors declare that they have no conflict of interest.

\section{References}

1. Weinreb RN, Aung T, Medeiros FA. The pathophysiology and treatment of glaucoma: a review. JAMA. 2014;311:1901-11.

2. Mi XS, Yuan TF, So KF. The current research status of normal tension glaucoma. Clin Interv Aging. 2014;9:1563-71.

3. Mastropasqua R, Fasanella V, Agnifili L, et al. Advance in the pathogenesis and treatment of normal-tension glaucoma. Prog Brain Res. 2015;221:213-32.

4. Mallick J, Devi L, Malik PK, Mallick J. Update on normal tension glaucoma. J Ophthalmic \& Vision Res. 2016;11:204-8.
5. Thonginnetra O, Greenstein VC, Chu D, Liebmann JM, Ritch R, Hood DC. Normal versus high tension glaucoma: a comparison of functional and structural defects. J Glaucoma. 2010;19:151-7.

6. King D, Drance SM, Douglas G, Schulzer M, Wijsman K. Comparison of visual field defects in normal-tension glaucoma and high-tension glaucoma. Am J Ophthalmol. 1986;101:204-7.

7. Cho HK, Lee J, Lee M, Kee C. Initial central scotomas vs peripheral scotomas in normal-tension glaucoma: clinical characteristics and progression rates. Eye. 2014;28:303-11.

8. Caprioli J, Sears M, Spaeth GL. Comparison of visual field defects in normal-tension glaucoma and high-tension glaucoma. Am J Ophthalmol. 1986;102:402-4.

9. Luo XG, Chiu K, Lau FH, Lee VW, Yung KK, So KF. The selective vulnerability of retinal ganglion cells in rat chronic ocular hypertension model at early phase. Cell Mol Neurobiol. 2009;29:1143-51.

10. Quigley HA, Broman AT. The number of people with glaucoma worldwide in 2010 and 2020. Br J Ophthalmol. 2006;90:262-7.

11. Thylefors B, Negrel AD. The global impact of glaucoma. Bull World Health Organ. 1994;72:323-6.

12. Grewe R. [The history of glaucoma]. Klin Mon Augenheilkd. 1986;188:167-9.

13. Graefe AV. Über die Iridectomie bei Glaucom und über den glaucomatösen Prozess. Albrecht Von Graefes Arch Klein Exp Ophthalmol. 1857;3:456.

14. Klein BE, Klein R, Sponsel WE, et al. Prevalence of glaucoma. The Beaver Dam Eye Study. Ophthalmology. 1992;99:1499-504.

15. Cho HK, Kee C. Population-based glaucoma prevalence studies in Asians. Surv Ophthalmol. 2014;59:434-47.

16. Collaborative Normal-Tension Glaucoma Study Group. The effectiveness of intraocular pressure reduction in the treatment of normal-tension glaucoma. Am J Ophthalmol. 1998;126:498-505.

17. Chen Y, Hughes G, Chen X, et al. Genetic variants associated with different risks for high tension glaucoma and normal tension glaucoma in a chinese population. Invest Ophthalmol Vis Sci. 2015;56:2595-600.

18. Rotchford AP, Johnson GJ. Glaucoma in Zulus: a populationbased cross-sectional survey in a rural district in South Africa. Arch Ophthalmol (Chic, Ill: 1960). 2002;120:471-8.

19. Dielemans I, Vingerling JR, Wolfs RC, Hofman A, Grobbee DE, de Jong PT. The prevalence of primary open-angle glaucoma in a population-based study in The Netherlands. The Rotterdam Study. Ophthalmology. 1994;101:1851-5.

20. Bonomi L, Marchini G, Marraffa M, et al. Prevalence of glaucoma and intraocular pressure distribution in a defined population. The Egna-Neumarkt Study. Ophthalmology. 1998;105:209-15.

21. Caprioli J, Spaeth GL. Comparison of the optic nerve head in high- and low-tension glaucoma. Arch Ophthalmol. 1985;103:1145-9.

22. Eid TE, Spaeth GL, Moster MR, Augsburger JJ. Quantitative differences between the optic nerve head and peripapillary retina in low-tension and high-tension primary open-angle glaucoma. Am J Ophthalmol. 1997;124:805-13.

23. Adlina AR, Alisa-Victoria K, Shatriah I, Liza-Sharmini AT, Ahmad MS. Optic disc topography in Malay patients with normal-tension glaucoma and primary open-angle glaucoma. Clin Ophthalmol (Auckl, NZ). 2014;8:2533-9.

24. Kiriyama N, Ando A, Fukui C, et al. A comparison of optic disc topographic parameters in patients with primary open angle glaucoma, normal tension glaucoma, and ocular hypertension. Graefe's Arch Clin Exp ophthalmol. 2003;241:541-5.

25. Burgoyne CF, Downs JC, Bellezza AJ, Suh JK, Hart RT. The optic nerve head as a biomechanical structure: a new paradigm 
for understanding the role of IOP-related stress and strain in the pathophysiology of glaucomatous optic nerve head damage. Prog Retin Eye Res. 2005;24:39-73.

26. Burgoyne CF. A biomechanical paradigm for axonal insult within the optic nerve head in aging and glaucoma. Exp Eye Res. 2011;93:120-32.

27. Fortune B, Reynaud J, Hardin C, Wang L, Sigal IA, Burgoyne CF. Experimental glaucoma causes optic nerve head neural rim tissue compression: a potentially important mechanism of axon injury. Invest Ophthalmol Vis Sci. 2016;57:4403-11.

28. Copt RP, Thomas R, Mermoud A. Corneal thickness in ocular hypertension, primary open-angle glaucoma, and normal tension glaucoma. Arch Ophthalmol. 1999;117:14-6.

29. Emara BY, Tingey DP, Probst LE, Motolko MA. Central corneal thickness in low-tension glaucoma. Can J Ophthalmol J Can d'ophtalmologie. 1999;34:319-24.

30. Shah S, Chatterjee A, Mathai M, et al. Relationship between corneal thickness and measured intraocular pressure in a general ophthalmology clinic. Ophthalmology. 1999;106:2154-60.

31. Wu LL, Suzuki Y, Ideta R, Araie M. Central corneal thickness of normal tension glaucoma patients in Japan. Jpn J Ophthalmol. 2000;44:643-7.

32. Chen HC, Ho JD, Chang SH, Chen YH, Wu SC. Central corneal thickness of normal-tension glaucoma and non-glaucoma populations in ethnic Chinese. Chang Gung Med J. 2004;27:50-5.

33. Lee JW, Wong RL, Chan JC, Wong IY, Lai JS. Differences in corneal parameters between normal tension glaucoma and primary open-angle glaucoma. Int Ophthalmol. 2015;35:67-72.

34. Lin W, Aoyama Y, Kawase K, Yamamoto T. Relationship between central corneal thickness and visual field defect in openangle glaucoma. Jpn J Ophthalmol. 2009;53:477-81.

35. Cao KY, Kapasi M, Betchkal JA, Birt CM. Relationship between central corneal thickness and progression of visual field loss in patients with open-angle glaucoma. Can J Ophthalmol J Can d'ophtalmologie. 2012;47:155-8.

36. Jaeger E. Über Glaukom und seine Heilung durch Iridektomie. Z Ges Aerzte Wein. 1858;14:465-91.

37. Yamazaki Y, Drance SM. The relationship between progression of visual field defects and retrobulbar circulation in patients with glaucoma. Am J Ophthalmol. 1997;124:287-95.

38. Katai N, Yoshimura N. Apoptotic retinal neuronal death by ischemia-reperfusion is executed by two distinct caspase family proteases. Invest Ophthalmol Vis Sci. 1999;40:2697-705.

39. Cioffi GA, Sullivan P. The effect of chronic ischemia on the primate optic nerve. Eur J Ophthalmol. 1999;9:S34-6.

40. Flammer J, Orgul S, Costa VP, et al. The impact of ocular blood flow in glaucoma. Prog Retin Eye Res. 2002;21:359-93.

41. Flammer J. The vascular concept of glaucoma. Surv Ophthalmol. 1994;38:Suppl: S3-6.

42. Hayreh SS, Zimmerman MB, Podhajsky P, Alward WL. Nocturnal arterial hypotension and its role in optic nerve head and ocular ischemic disorders. Am J Ophthalmol. 1994;117:603-24.

43. Meyer JH, Brandi-Dohrn J, Funk J. Twenty four hour blood pressure monitoring in normal tension glaucoma. $\mathrm{Br} \mathrm{J}$ Ophthalmol. 1996;80:864-7.

44. Graham SL, Drance SM. Nocturnal hypotension: role in glaucoma progression. Surv Ophthalmol. 1999;43:S10-6.

45. Leighton DA, Phillips CI. Systemic blood pressure in open-angle glaucoma, low tension glaucoma, and the normal eye. $\mathrm{Br} \mathrm{J}$ Ophthalmol. 1972;56:447-53.

46. Choi J, Kim KH, Jeong J, Cho HS, Lee CH, Kook MS. Circadian fluctuation of mean ocular perfusion pressure is a consistent risk factor for normal-tension glaucoma. Invest Ophthalmol Vis Sci. 2007;48:104-11.
47. Okumura Y, Yuki K, Tsubota K. Low diastolic blood pressure is associated with the progression of normal-tension glaucoma. Ophthalmologica. 2012;228:36-41.

48. Buckley C, Hadoke PW, Henry E, O'Brien C. Systemic vascular endothelial cell dysfunction in normal pressure glaucoma. $\mathrm{Br} \mathrm{J}$ Ophthalmol. 2002;86:227-32.

49. Gasser P, Flammer J, Guthauser U, Mahler F. Do vasospasms provoke ocular diseases? Angiology. 1990;41:213-20.

50. Pache M, Dubler B, Flammer J. Peripheral vasospasm and nocturnal blood pressure dipping--two distinct risk factors for glaucomatous damage? Eur J Ophthalmol. 2003;13:260-5.

51. Drance S, Anderson DR, Schulzer M. Risk factors for progression of visual field abnormalities in normal-tension glaucoma. Am J Ophthalmol. 2001;131:699-708.

52. Tian T, Liu YH. Normal-tension glaucoma and Alzheimer's disease: retinal vessel signs as a possible common underlying risk factor. Med Hypotheses. 2011;77:466.

53. Hayreh SS. The role of age and cardiovascular disease in glaucomatous optic neuropathy. Surv Ophthalmol. 1999;43:S27-42.

54. De Moraes CG, Juthani VJ, Liebmann JM, et al. Risk factors for visual field progression in treated glaucoma. Arch Ophthalmol. 2011;129:562-8.

55. Flammer J, Mozaffarieh M. What is the present pathogenetic concept of glaucomatous optic neuropathy? Surv Ophthalmol. 2007;52:S162-73.

56. Onen SH, Mouriaux F, Berramdane L, Dascotte JC, Kulik JF, Rouland JF. High prevalence of sleep-disordered breathing in patients with primary open-angle glaucoma. Acta Ophthalmol Scand. 2000;78:638-41.

57. Mojon DS, Hess CW, Goldblum D, et al. High prevalence of glaucoma in patients with sleep apnea syndrome. Ophthalmology. 1999;106:1009-12.

58. Su WW, Cheng ST, Hsu TS, Ho WJ. Abnormal flow-mediated vasodilation in normal-tension glaucoma using a noninvasive determination for peripheral endothelial dysfunction. Invest Ophthalmol Vis Sci. 2006;47:3390-4.

59. Galassi F, Giambene B, Varriale R. Systemic vascular dysregulation and retrobulbar hemodynamics in normal-tension glaucoma. Invest Ophthalmol Vis Sci. 2011;52:4467-71.

60. Sugiyama T, Moriya S, Oku H, Azuma I. Association of endothelin-1 with normal tension glaucoma: clinical and fundamental studies. Surv Ophthalmol. 1995;39:S49-56.

61. Cellini M, Possati GL, Profazio V, Sbrocca M, Caramazza N, Caramazza R. Color doppler imaging and plasma levels of endothelin-1 in low-tension glaucoma. Acta Ophthalmol Scand Suppl. 1997;224:11-3.

62. Kunimatsu S, Mayama C, Tomidokoro A, Araie M. Plasma endothelin-1 level in Japanese normal tension glaucoma patients. Curr Eye Res. 2006;31:727-31.

63. Quigley HA, Hohman RM, Addicks EM, Massof RW, Green WR. Morphologic changes in the lamina cribrosa correlated with neural loss in open-angle glaucoma. Am J Ophthalmol. 1983;95:673-91.

64. Stowell C, Burgoyne CF, Tamm ER, Ethier CR. Biomechanical aspects of axonal damage in glaucoma: A brief review. Exp Eye Res. 2017;157:13-9.

65. Jonas JB, Wang N, Yang D. Translamina cribrosa pressure difference as potential element in the pathogenesis of glaucomatous optic neuropathy. Asia-Pac J Ophthalmol. 2016;5:5-10.

66. Morgan WH, Yu DY, Cooper RL, Alder VA, Cringle SJ, Constable IJ. The influence of cerebrospinal fluid pressure on the lamina cribrosa tissue pressure gradient. Invest Ophthalmol Vis Sci. 1995;36:1163-72.

67. Yablonski M, Ritch R, Pokorny KS. Effect of decreased intracranial pressure on optic disc. Invest Ophthalmol Vis Sci. 1979;18:165. 
68. Ren R, Jonas JB, Tian G, et al. Cerebrospinal fluid pressure in glaucoma: a prospective study. Ophthalmology. 2010;117: 259-66.

69. Berdahl JP, Fautsch MP, Stinnett SS, Allingham RR. Intracranial pressure in primary open angle glaucoma, normal tension glaucoma, and ocular hypertension: a case-control study. Invest Ophthalmol Vis Sci. 2008;49:5412-8.

70. Pircher A, Remonda L, Weinreb RN, Killer HE. Translaminar pressure in Caucasian normal tension glaucoma patients. Acta Ophthalmol (Copenh). 2017;95:e524-31.

71. Linden C, Qvarlander S, Johannesson G, et al. Normal-tension glaucoma has normal intracranial pressure: a prospective study of intracranial pressure and intraocular pressure in different body positions. Ophthalmology. 2017;1-8.

72. Davison H. Physiology of the cerebrospinal fluid. London: J \& A Churchil Ltd; 1967.

73. Hardy J, Selkoe DJ. The amyloid hypothesis of Alzheimer's disease: progress and problems on the road to therapeutics. Science. 2002;297:353-6.

74. Tarasoff-Conway JM, Carare RO, Osorio RS, et al. Clearance systems in the brain-implications for Alzheimer disease. Nat Rev Neurol. 2015;11:457-70.

75. Chiu C, Miller MC, Caralopoulos IN, et al. Temporal course of cerebrospinal fluid dynamics and amyloid accumulation in the aging rat brain from three to thirty months. Fluids Barriers CNS. 2012;9:3.

76. Silverberg GD, Mayo M, Saul T, Rubenstein E, McGuire D. Alzheimer's disease, normal-pressure hydrocephalus, and senescent changes in CSF circulatory physiology: a hypothesis. Lancet Neurol. 2003;2:506-11.

77. Lai SW, Lin CL, Liao KF. Glaucoma may be a non-memory manifestation of Alzheimer's disease in older people. Int Psychogeriatr. 2017:1-7.

78. Mancino R, Martucci A, Cesareo M, et al. Glaucoma and alzheimer disease: a single age-related neurodegenerative disease of the brain. Curr Neuropharmacol. 2017;15:1-7.

79. Cesareo M, Martucci A, Ciuffoletti E, et al. Association between alzheimer's disease and glaucoma: a study based on Heidelberg retinal tomography and frequency doubling technology perimetry. Front Neurosci. 2015;9:479.

80. Silverberg GD, Heit G, Huhn S, et al. The cerebrospinal fluid production rate is reduced in dementia of the Alzheimer's type. Neurology. 2001;57:1763-6.

81. Serot JM, Zmudka J, Jouanny P. A possible role for CSF turnover and choroid plexus in the pathogenesis of late onset Alzheimer's disease. J Alzheimer's Dis: JAD. 2012;30:17-26.

82. Liu YH, Tian T. Hypothesis of optineurin as a new common risk factor in normal-tension glaucoma and Alzheimer's disease. Med Hypotheses. 2011;77:591-2.

83. Tsolaki F, Gogaki E, Tiganita S, et al. Alzheimer's disease and primary open-angle glaucoma: is there a connection? Clin Ophthalmol. 2011;5:887-90.
84. Killer HE, Miller NR, Flammer J, et al. Cerebrospinal fluid exchange in the optic nerve in normal-tension glaucoma. $\mathrm{Br} \mathrm{J}$ Ophthalmol. 2012;96:544-8.

85. Pircher A, Montali M, Berberat J, Remonda L, Killer HE. The optic canal: a bottleneck for cerebrospinal fluid dynamics in normal-tension glaucoma? Front Neurol. 2017;8:47.

86. Killer HE, Jaggi GP, Flammer J, Miller NR, Huber AR. The optic nerve: a new window into cerebrospinal fluid composition? Brain: a J Neurol. 2006;129:1027-30.

87. Kaeslin MA, Killer HE, Fuhrer CA, Zeleny N, Huber AR, Neutzner A. Changes to the aqueous humor proteome during glaucoma. PloS ONE. 2016;11:e0165314.

88. Bauer G, Killer HE, Forrer A, Huber AR, Jaggi GP. Lipocalinlike prostaglandin D synthase (L-PGDS) concentration in aqueous humour in patients with open-angle glaucoma. J Glaucoma. 2014;23:164-8.

89. Jaggi GP, Harlev M, Ziegler U, Dotan S, Miller NR, Killer HE. Cerebrospinal fluid segregation optic neuropathy: an experimental model and a hypothesis. $\mathrm{Br} \mathrm{J}$ Ophthalmol. 2010;94:1088-93.

90. Andrews RM, Griffiths PG, Johnson MA, Turnbull DM. Histochemical localisation of mitochondrial enzyme activity in human optic nerve and retina. Br J Ophthalmol. 1999;83:231-5.

91. Killer HE, Subramanian PS. Compartmentalized cerebrospinal fluid. Int Ophthalmol Clin. 2014;54:95-102.

92. Liu Y, Allingham RR. Major review: Molecular genetics of primary open-angle glaucoma. Exp Eye Res. 2017;160:62-84.

93. Fingert JH, Robin AL, Stone JL, et al. Copy number variations on chromosome $12 \mathrm{q} 14$ in patients with normal tension glaucoma. Hum Mol Genet. 2011;20:2482-94.

94. Rezaie T, Child A, Hitchings R, et al. Adult-onset primary openangle glaucoma caused by mutations in optineurin. Science. 2002;295:1077-9.

95. Awadalla MS, Fingert JH, Roos BE, et al. Copy number variations of TBK1 in Australian patients with primary open-angle glaucoma. Am J Ophthalmol. 2015;159:124-30.e1.

96. Yang Z, Klionsky DJ. Mammalian autophagy: core molecular machinery and signaling regulation. Curr Opin Cell Biol. 2010;22:124-31.

97. Tucker BA, Solivan-Timpe F, Roos BR, et al. Duplication of TBK1 stimulates autophagy in iPSC-derived retinal cells from a patient with normal tension glaucoma. J Stem Cell Res Ther. 2014;3:161.

98. Wostyn P, De Groot V, Van Dam D, Audenaert K, De Deyn PP. Senescent changes in cerebrospinal fluid circulatory physiology and their role in the pathogenesis of normal-tension glaucoma. Am J Ophthalmol. 2013;156:5-14.

99. Wostyn P, De Groot V, Van Dam D, Audenaert K, Killer HE, De Deyn PP. Glaucoma considered as an imbalance between production and clearance of neurotoxins. Invest Ophthalmol Vis Sci. 2014;55:5351-2.

100. Giorgio A, Zhang J, Costantino F, De Stefano N, Frezzotti P. Diffuse brain damage in normal tension glaucoma. Hum Brain Mapp. 2017;39:532-41. 